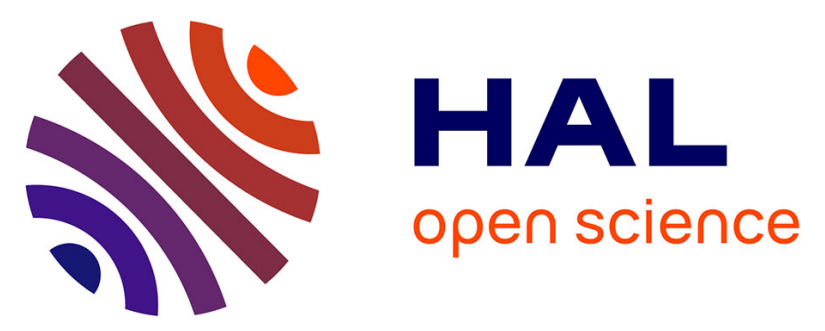

\title{
Study of interactions between carboxylated core shell magnetic nanoparticles and polymyxin B by capillary electrophoresis with inductively coupled plasma mass spectrometry
}

Daniel Baron, Jan Rozsypal, Aude Michel, Emilie Secret, Jean-Michel Siaugue, Tomáš Pluháček, Jan Petr

\section{To cite this version:}

Daniel Baron, Jan Rozsypal, Aude Michel, Emilie Secret, Jean-Michel Siaugue, et al.. Study of interactions between carboxylated core shell magnetic nanoparticles and polymyxin B by capillary electrophoresis with inductively coupled plasma mass spectrometry. Journal of Chromatography A, 2020, 1609, pp.460433. 10.1016/j.chroma.2019.460433 . hal-03043815

\section{HAL Id: hal-03043815 https://hal.science/hal-03043815}

Submitted on 7 Dec 2020

HAL is a multi-disciplinary open access archive for the deposit and dissemination of scientific research documents, whether they are published or not. The documents may come from teaching and research institutions in France or abroad, or from public or private research centers.
L'archive ouverte pluridisciplinaire $\mathbf{H A L}$, est destinée au dépôt et à la diffusion de documents scientifiques de niveau recherche, publiés ou non, émanant des établissements d'enseignement et de recherche français ou étrangers, des laboratoires publics ou privés. 
Short communication

Study of interactions between carboxylated core shell magnetic nanoparticles and polymyxin B by capillary electrophoresis with inductively coupled plasma mass spectrometry

Daniel Baron ${ }^{1}$, Jan Rozsypal ${ }^{1}$, Aude Michel $^{2}$, Emilie Secret $^{2}$, Jean-Michel Siaugue ${ }^{2}$, Tomáš Pluháček ${ }^{1 *}, J_{a n} \operatorname{Petr}^{1 *}$

${ }^{1}$ Department of Analytical Chemistry, Regional Centre of Advanced Technologies and Materials, Faculty of Science, Palacký University in Olomouc, 17. listopadu 12, 77146 Olomouc, Czech Republic

${ }^{2}$ Sorbonne Université, CNRS, Physico-chimie des Électrolytes et Nanosystèmes Interfaciaux, PHENIX, F-75005 Paris, France

\section{*Correspondence:}

Dr. Tomáš Pluháček

E-mail: tomas.pluhacek@upol.cz; Phone: +420-585-63-4542

Dr. Jan Petr

E-mail: jan.petr@upol.cz; Phone: +420-585-63-4416

\section{Keywords:}

Capillary electrophoresis; Inductively coupled plasma mass spectrometry; Interaction;

Nanoparticles

\section{ORCID:}

Daniel Baron 0000-0003-1607-2458

Jan Rozsypal 0000-0003-3168-7362

Emilie Secret 0000-0003-2200-7265

Jean-Michel Siaugue 0000-0003-1217-9493

Tomáš Pluháček 0000-0002-7417-0016

Jan Petr

0000-0002-9961-6459 
1 Abbreviations:

$2 \mathrm{CE}$, capillary electrophoresis; ICP-MS, inductively coupled plasma mass spectrometry; PMB,

3 Polymyxin B sulfate

4

\section{Abstract}

6 In this work, interactions of carboxylated core shell magnetic nanoparticles with polymyxin B

7 sulfate were studied by connecting capillary electrophoresis with inductively coupled plasma

8 mass spectrometry. The interaction was probed by affinity mode of capillary electrophoresis

9 with $25 \mathrm{mM}$ phosphate buffer at physiological $\mathrm{pH} .{ }^{54} \mathrm{Fe},{ }^{56} \mathrm{Fe},{ }^{57} \mathrm{Fe},{ }^{34} \mathrm{~S}$, and ${ }^{12} \mathrm{C}$ isotopes were used to monitor the migration of an electroosmotic flow marker and the interaction of the nanoparticles with polymyxin B. The analysis of interaction data showed two distinct interaction regions, one with low polymyxin B concentration, the second with high polymyxin $\mathrm{B}$ concentration. These regions differed in the strength of the interaction, $14.9 \times 10^{6} \mathrm{M}^{-1}$ and $16.0 \times 10^{3} \mathrm{M}^{-1}$, and in the stoichiometry of 0.7 and 3.5 , respectively. These differences can be explained by the decrease of electrostatic repulsion between nanoparticles caused by polymyxin B. This is also in agreement with the nanoparticles peak shapes: sharp for low polymyxin B concentrations and broad for high polymyxin B concentrations.

(1)

(1)

3

4

5


2 The recent developments in nanotechnology and the emerging use of various types of nanoparticles (NPs) in industry, environment or medicine have raised questions about the behavior of NPs when in the presence of other (bio)molecules as well as concerns about their potential impact on human health. Although the chemical composition of nanomaterials may not be significantly different from bulk materials, their physicochemical properties and their interactions with biological systems dramatically change due to their nanoscale dimension [1]. Currently, there is a strong demand for the development and validation of new highthroughput methodologies that are reliable and accurate for the characterization and quantification of NPs in various kinds of biological samples. As it has already been reported, NPs can interact with many (bio)molecules (such as proteins, DNA, etc.), and the resulting NPs coat could form a protective layer that can increase NPs stability, water solubility and biocompatibility $[2,3]$. The protein corona causes numerous biological responses of NPs, such as facilitating cell internalization [4]. Protein binding is also one of the key aspects affecting the biodistribution of NPs throughout the body [5]. This can be beneficial for applications such as diagnosis or drug delivery. However, it was found that NPs can initiate and catalyze protein aggregation, denaturation and misfolding $[6,7]$ and can, moreover, disrupt protein-protein interactions [8], possibly resulting in protein malfunctioning and, therefore, adverse biological effects [9].

As mentioned, the study of non-covalent molecular interactions is important due to their high significance in various (bio)chemical and biological processes. Strength of the non-covalent interactions between two interacting compounds, 'A' and ' $\mathrm{L}$ ', is characterized by the apparent binding (association) constants that are defined by the following:

$$
\begin{gathered}
\mathrm{A}+\mathrm{L} \rightleftarrows \mathrm{AL} \\
K_{b}=\frac{[A L]}{[A][L]}
\end{gathered}
$$

Here, $[\mathrm{A}],[\mathrm{L}]$ and $[\mathrm{AL}]$ are equilibrium molar concentrations of analyte, ligand and their complex, respectively.

These constants can be determined by a variety of physico-chemical methods [10-15]. Here, capillary electrophoresis (CE), which is well known not only as an efficient separation technique but also as a viable tool to study chemical reactions, including kinetic measurements and the analysis of chemical equilibria [16], features several benefits such as 
high separation efficiency, short analysis time periods, high mass sensitivity, very low chemical and sample consumptions and the characterization of interacting species in a solution [17]. Therefore, CE in the affinity capillary electrophoresis mode (ACE) is a powerful technique for the characterization of NPs and their interaction with other (bio)molecules [18-25]. In ACE, increasing amounts of ligands are simply added to the running buffer, leading to changes in the migration time of the interacting analyte. The binding constant between the ligand and the analyte is then calculated from the effective mobilities of the analyte [10, 26-28].

However, sometimes CE is not applicable in complex media because of matrix interference, and thus requires complex sample preparation procedures. Moreover, the benefits of CE can be overshadowed by the low sensitivity of UV detection systems, which are commonly used $[29,30]$. This can be solved by coupling of a CE with an electrospray ionization mass spectrometry (ESI-MS), which can directly provide stoichiometric information on the complex and simultaneously detect several components [12]. However, the major problem in connecting CE with ESI-MS lies in the necessity of using volatile "MS-compatible" running buffers and migration systems in CE, since the non-volatile components do not reach the ESI source [31].

Nevertheless, another interesting possibility exists that can solve these issues: CE connected to inductively coupled plasma mass spectrometry (ICP-MS). ICP-MS is capable of achieving multi-element determination of ultra-trace concentration levels of metal and metalloid containing compounds. In addition to its low detection limits and excellent sensitivity, the linear dynamic range of ICP-MS allows for the simultaneous detection of both major and trace components at the same sample dilution $[32,33]$. Therefore, CE-ICP-MS seems to be one of the few analytical tools that can be employed to understand the fate of metal-based drugs in the body and the body's mechanisms of action at the molecular level, as well as in metabolomic analysis [34, 35]. Moreover, CE coupled with ICP-MS still provides stoichiometric, thermodynamic and kinetic information about the interactions between metal species and (bio)molecules [36-38]. Additionally, CE interfaced with ICP-MS has shown a strong potential for directly analyzing nanomaterials in complex media without any extraction or extensive sample preparation steps [39]. 
1 In the work presented here, the interactions between carboxylated core-shell magnetic NPs

$2\left(\mathrm{Fe}_{2} \mathrm{O}_{3} @ \mathrm{SiO}_{2} \mathrm{COOH} \mathrm{NPs}\right)$ and polymyxin $\mathrm{B}$ sulfate were analyzed using CE-ICP-MS. CE-

3 ICP-MS was chosen because it allows detecting specific metal species and hence it can be used for correct determination of migration times of interacting species (in comparison with CE-DAD). Polymyxin B, an antibiotic primarily used to treat resistant bacterial infections, was selected as a model antibiotic in the view of development a microdevice to test bacterial resistance. The microbial resistance to antibiotics represents a huge well-known problem in medicine related to the excessive use of antibiotics as well as unhealthy life style [40]. It is interesting that a lot of NPs have antibacterial activity [41], however, resistance of bacteria to NPs was also described [42]. The microdevice, schematically shown in Fig. S1 in the supporting material, is based on the formation of 3D-printed straight channel, its insertion into PDMS and its removal [43]. The NPs with polymyxin B are captured in the device by using magnetic field and when they are in contact with bacterial cells, they are releasing polymyxin $\mathrm{B}$ according to the cells' resistance. In order to proof and tune the performance of the microdevice, the quantitative description of the interaction of $\mathrm{Fe}_{2} \mathrm{O}_{3} @ \mathrm{SiO}_{2} \mathrm{COOH}$ NPs with polymyxin B is necessary. Interestingly, the results can be also used in the case of application of these NPs for the treatment of wastewaters contaminated by antibiotics $[44,45]$.

\section{Experimental}

\subsection{Chemicals}

All the chemicals were purchased from Sigma-Aldrich (St. Louis, MO, USA), except for polymyxin B sulfate, which was from SERVA (FeinBiochemica, Heidelberg/New York) and 2-[methoxy(polyethyleneoxy)propyl]-trimethoxysilane, which was from ABCR (Karlsruhe, Germany). A single element aqueous calibration standard of $\mathrm{Fe}\left(\mathrm{c}=1,000 \pm 2 \mathrm{mg} . \mathrm{L}^{-1}\right)$ diluted to $100 \mu \mathrm{g} . \mathrm{L}^{-1}$ was purchased from ASTASOL (Analytika, Prague, Czech Republic) for the fine tuning of ICP-MS parameters. Tuning solution of $\mathrm{Li}, \mathrm{Y}, \mathrm{Ce}$ and $\mathrm{Tl}\left(\mathrm{c}=1 \mu \mathrm{g} . \mathrm{L}^{-1}\right)$ was purchased from Agilent Technologies (Tokyo, Japan). The background electrolytes (BGEs) were prepared by dissolving the needed amount of phosphoric acid and adjusting the $\mathrm{pH}$ of this solution to 7.4 with $\mathrm{NaOH}$. Ultrapure water (resistivity of $18.2 \mathrm{M} \Omega . \mathrm{cm}$, MilliQ, Millipore) was used to prepare all solutions.

\subsection{Synthesis and characterization of nanoparticles}

The $\mathrm{Fe}_{2} \mathrm{O}_{3} @ \mathrm{SiO}_{2} \mathrm{COOH}$ NPs were synthesized according to reported protocols [46, 47]. 
1 In brief, magnetic maghemite NPs $\left(\gamma-\mathrm{Fe}_{2} \mathrm{O}_{3}, 7 \mathrm{~nm}\right.$ mean diameter) were prepared following

2 the procedure described by Massart and were subsequently coated with citrate anions [48, 49].

3 Citrated maghemite NPs $\left(\mathrm{V}=300 \mu \mathrm{L}, \mathrm{nFe}=4.0 \times 10^{-4} \mathrm{~mol}\right)$ were coated with a thick silica shell by condensing tetraethylorthosilicate $\left(\mathrm{V}=600 \mu \mathrm{L}, \mathrm{n}=2.7 \times 10^{-3} \mathrm{~mol}\right)$ in the presence of ammonia $\left(\mathrm{V}=1.25 \mathrm{~mL}, \mathrm{n}=1.9 \times 10^{-2} \mathrm{~mol}\right)$ in a mixture of water $(\mathrm{V}=25 \mathrm{~mL})$ and ethanol $(\mathrm{V}$ $=50 \mathrm{~mL}$ ). The silica shell surface functionalization with $\mathrm{NH}_{2}$ groups and short polyethyleneglycol (PEG) chains was performed in a second step by the simultaneous condensation of (3-aminopropyl)triethoxysilane $\left(\mathrm{V}=100 \mu \mathrm{L}, \mathrm{n}=4.2 \times 10^{-4} \mathrm{~mol}\right)$ and a silica PEG-derived compound, 2-[methoxy(polyethyleneoxy)propyl]trimethoxysilane (V = 230 $\mu \mathrm{L}$, $\left.\mathrm{n}=4.2 \times 10^{-4} \mathrm{~mol}\right)$, with an appropriate amount of tetraethylorthosilicate $(\mathrm{V}=200 \mu \mathrm{L}, \mathrm{n}=$ $8.97 \times 10^{-4} \mathrm{~mol}$ ) in order to generate a cross-linked silica shell. The NPs were then dispersed in $25 \mathrm{~mL}$ of 3-(N-morpholino)propanesulfonic acid (MOPS) buffer at $0.1 \mathrm{M}$ at $\mathrm{pH}$ 7.4. The $\mathrm{Fe}_{2} \mathrm{O}_{3} @ \mathrm{SiO}_{2} \mathrm{NH}_{2} \mathrm{NPs}$ were then converted to $\mathrm{Fe}_{2} \mathrm{O}_{3} @ \mathrm{SiO}_{2} \mathrm{COOH}$ NPs via an overnight reaction of $11 \mathrm{~mL}$ of this dispersion of NPs with succinic anhydride $\left(\mathrm{m}=1.438 \mathrm{~g}, \mathrm{n}=1.4 \times 10^{-}\right.$ 2 mol). Finally, the NPs were washed with MOPS buffer in PD-10 columns containing Sephadex G-25 (GE Healthcare).

The iron concentration in the $\mathrm{Fe}_{2} \mathrm{O}_{3} @ \mathrm{SiO}_{2} \mathrm{COOH}$ NPs was measured to be $7.8 \times 10^{-3}$ mol. $\mathrm{L}^{-1}$. The NPs were then characterized by atomic force microscopy (AFM), dynamic light scattering (DLS) and zetametry. Dimension Icon atomic force microscope (Bruker, Santa Barbara, USA) with NanoScope 9.1 software was employed for topography measurement. The NP sample was diluted 10,000 times with deionized water from a stock dispersion of $\mathrm{Fe}_{2} \mathrm{O}_{3} @ \mathrm{SiO}_{2} \mathrm{COOH}$ NPs. Of this sample, $5 \mu 1$ were deposited on a freshly cleaved mica substrate (SPI Chem Mica, grade V-4 muscovite, SPI supplies) and left to dry in a desiccator. A ScanAsyst Air AFM tip with a reflective Al coating on the cantilever back side (nominal resonant frequency $70 \mathrm{kHz}$ and nominal force constant $0.4 \mathrm{~N} . \mathrm{m}^{-1}$ ) was used. Images were obtained in PeakForce tapping mode at a scan rate of $0.501 \mathrm{~Hz}$ and a resolution of 512 pixels and were processed using NanoScope Analysis 1.5 software. The diameter of the NPs was measured to be $60 \pm 5 \mathrm{~nm}$. See Figure $S 2$ in the supporting material.

Both the zeta potential and hydrodynamic size of the NPs were measured with a Zetasizer Nano S90 (Malvern Instruments, Worcestershire, UK), using the following parameters: refractive index: 2.42 , viscosity: $0.8872 \mathrm{cP}$, temperature: $25^{\circ} \mathrm{C}$, medium: water, material absorbance: 0.01 , refractive index of medium: 1.330 , detection angle: $173^{\circ}$, wavelength 633 
$\mathrm{nm}$. The zeta potential and hydrodynamic size of the NPs were measured to be $-13.9 \pm 1.1$ $\mathrm{mV}$ and $71.5 \pm 0.1 \mathrm{~nm}$ respectively (see Fig. $\mathrm{S} 3$ in the supporting material), both of which were measured in the phosphate buffer $\mathrm{pH}$ 7.4.

\subsection{CE and ICP-MS apparatus and conditions}

All the CE-ICP-MS experiments were carried out using the capillary electrophoresis instrument CE7100, Agilent Technologies (Waldbronn, Germany). Separations were performed in fused silica capillary with a length of $47 \mathrm{~cm}$ and an internal diameter of $50 \mu \mathrm{m}$ (Molex, Lisle, IL, USA) by applying a separation voltage of $25 \mathrm{kV}$. The temperature of the capillary cassette was set to $25^{\circ} \mathrm{C}$. Prior to their first use, the capillaries were initially conditioned by being flushed with $0.1 \mathrm{~mol} . \mathrm{L}^{-1} \mathrm{NaOH}$ for 20 minutes and then with deionized water for another 20 minutes. Between each sample run, the capillaries were re-conditioned by rinsing them with 0.1 mol. $\mathrm{L}^{-1} \mathrm{NaOH}$ (two minutes), deionized water (two minutes) and the BGEs (four minutes). All the rinses were performed using a pressure drop of 935 mbar. The sample was injected at 50 mbar for five seconds. Samples consisted of 100-fold diluted dimethyl sulfoxide (which served as a marker of electroosmosis) and 50-fold diluted $\mathrm{Fe}_{2} \mathrm{O}_{3} @ \mathrm{SiO}_{2} \mathrm{COOH}$ NPs in deionized water.

The coupling of CE with a 7700x inductively coupled plasma mass spectrometer (Agilent Technologies, Tokyo, Japan) equipped with an octopole reaction system was achieved with a lab-made interface. The CE-ICP-MS interface was built using a cross-piece, a grounding electrode, an inlet for sheath liquid (placed in the inlets of the cross-piece) and a MicroMist concentric nebulizer. The sheath liquid (20 times diluted buffer solution without polymyxin B) was introduced by a self-aspiration into the nebulizer inlet, where it was directly mixed with the effluent from the CE capillary. The CE capillary goes through a cross-piece toward the inlet of the MicroMist concentric nebulizer and ends approximately one millimeter away from the beginning of the inner capillary.

Prior to each CE-ICP-MS hyphenation, the instrumental performance (such as the torch position, the argon flow rate, etc.) was optimized with a standard solution of $1 \mu \mathrm{g} . \mathrm{L}^{-1}$ of $\mathrm{Li}, \mathrm{Y}$, $\mathrm{Ce}, \mathrm{Tl}$, while a standard solution of Fe prepared in diluted buffer $\left(100 \mu \mathrm{g} . \mathrm{L}^{-1}\right)$ was used for the fine tuning of the CE-ICP-MS (especially ion optic and the flow rate of He throughout the collision cell) to achieve the maximum signal intensity for all measured iron isotopes. The optimized ICP-MS instrumental conditions were as follows: RF power of $1550 \mathrm{~W}$, plasma gas 
1 flow rate of $14.95 \mathrm{~L} \cdot \mathrm{min}^{-1}$, auxiliary gas flow rate of $0.9 \mathrm{~L} \cdot \mathrm{min}^{-1}$, nebulizer gas flow rate of

2 1.1 L.min ${ }^{-1}$, make up gas flow rate of $0.25 \mathrm{~L} \cdot \mathrm{min}^{-1}$, He flow rate in collision cell of $3 \mathrm{~mL} \cdot \mathrm{min}$

$3 \quad{ }^{1}$ and dwell time $100 \mathrm{~ms}$ for ${ }^{12} \mathrm{C},{ }^{34} \mathrm{~S},{ }^{54} \mathrm{Fe},{ }^{56} \mathrm{Fe}$ and ${ }^{57} \mathrm{Fe}$ isotopes (despite the identical results

4 for all iron isotopes, the most abundant ${ }^{56} \mathrm{Fe}$ isotope was used for the mobility evaluation; see

$5 \quad$ Fig. S4 in the supporting material). In addition, the signal of ${ }^{34} \mathrm{~S}$ isotope was used not only as

6 a marker of electroosmotic flow, but also to monitor the stability of the CE-ICP-MS

7 connection based on the analysis of the sulfur throughout the CE-ICP-MS analysis. The ratio

8 of ${ }^{56} \mathrm{Fe}$ and ${ }^{34} \mathrm{~S}$ isotopes peak area did not exceed 1.2 (SD 0.2, $\left.\mathrm{n}=16\right)$ in the whole concentration range of polymyxin B showing excellent stability of the CE-ICP-MS connection.

\subsection{ACE theory}

In the ACE mode, the analyte A is injected and migrates through the electrolyte containing the ligand L. The effective mobility of the analyte in equilibrium with the ligand $\mu_{\mathrm{A}}^{\mathrm{eff}}$ is the average of the actual mobility of both the free $\mu_{\mathrm{A}}^{0}$ and bound $\mu_{\mathrm{AL}}^{0}$ forms of the analyte, weighted by the molar fraction. If combined with eq. 2 , the effective mobility of the analyte in equilibrium with the ligand could be expressed as follows:

$$
\mu_{\mathrm{A}}^{\mathrm{eff}}=\frac{1}{1+K_{b}[\mathrm{~L}]} \mu_{\mathrm{A}}^{0}+\frac{K_{b}[\mathrm{~L}]}{1+K_{b}[\mathrm{~L}]} \mu_{\mathrm{AL}}^{0}
$$

In order to apply eq. 3, the equilibrium ligand concentration should be constant during the separation and should be known. It is common practice to substitute the equilibrium ligand concentration with the free ligand concentration, supposing that the analyte concentration does not overtake the ligand concentration. It is recommended that the ligand concentration should be higher than the analyte concentration of one order of magnitude [50].

Generally, the treatment of the relation between analyte effective mobilities and ligand concentrations is based on non-linear or linear regression [51, 52]. In our case, the $\mathrm{x}$ reciprocal method, which is sometimes called the Scatchard plot, was used to treat the data. The equation of the Scatchard plot could be written as follows:

$$
\frac{\mu_{\mathrm{A}}^{\text {eff }}-\mu_{\mathrm{A}}^{0}}{[\mathrm{~L}]}=-K_{b}\left(\mu_{\mathrm{A}}^{\text {eff }}-\mu_{\mathrm{A}}^{0}\right)+n K_{b}\left(\mu_{\mathrm{AL}}^{0}-\mu_{\mathrm{A}}^{0}\right)
$$


1 Here, $n$ is the stoichiometric ratio between the analyte and the ligand. This linearization procedure used to be one of the most common linearization methods for cases where the determination of binding constants is performed with various techniques $[51,53]$.

\section{$3 \quad$ Results and discussion}

In order to prove that the $\mathrm{Fe}_{2} \mathrm{O}_{3} @ \mathrm{SiO}_{2} \mathrm{COOH}$ NPs can be used for capturing polymyxin $\mathrm{B}$ in a microdevice for testing bacterial resistance, we studied the strength of the interaction by using the CE-ICP-MS connection. CE-ICP-MS was used instead of CE-DAD because it allows detecting isotopes and therefore it allows correct determination of migration times of interacting species; see an example of CE-DAD profiles in Fig. S5 in the supporting material. A typical ACE setup was used; polymyxin B was added to the running $25 \mathrm{mM}$ phosphate buffer at a physiological pH of 7.4 and the mobilities of NPs were studied in detail. The choice of running buffer composition and $\mathrm{pH}$ was in accordance with the subsequent use of the setup in the proposed microdevice. The concentration of polymyxin B varied from 0 to $250 \times 10^{-7}$ mol. $\mathrm{L}^{-1}$. Higher concentrations of polymyxin B were not studied because aggregation of NPs was observed (> $\left.350 \times 10^{-7} \mathrm{~mol} . \mathrm{L}^{-1}\right)$. Fig. 1 shows an example of the CEICP-MS analysis of the $\mathrm{Fe}_{2} \mathrm{O}_{3} @ \mathrm{SiO}_{2} \mathrm{COOH}$ NPs with different polymyxin B concentrations. Isotopes ${ }^{34} \mathrm{~S}$ (from DMSO) and ${ }^{56} \mathrm{Fe}$ (from NPs) were used for calculating the NP mobilities. The dependence of effective mobilities of NPs on concentrations of polymyxin B (Fig. 2A) shows two distinct interaction regions with concentrations of polymyxin $\mathrm{B}$ of $1-50 \times 10^{-7}$ mol. $\mathrm{L}^{-1}$ and $100-250 \times 10^{-7}$ mol.L $\mathrm{L}^{-1}$. The transitional concentrations region $\left(50-100 \times 10^{-7}\right.$ mol. $\mathrm{L}^{-1}$ ) represents the area where the interaction mechanism is probably changing.

Interestingly, the two interaction regions also differed with respect to the peak shape of NPs. While the NPs formed quite sharp peaks in the BGEs with low polymyxin B concentrations, they created broad zones in high polymyxin B concentrations (see also Fig. 1). In order to be sure that these broad zones corresponded to NPs interacting with polymyxin B, pressureassisted CE-ICP-MS was performed. The NPs were analyzed in the phosphate buffer with an addition of $300 \times 10^{-7}$ mol. $\mathrm{L}^{-1}$ polymyxin $\mathrm{B}$ under the pressure drop of $50 \mathrm{mbar}$. The ${ }^{12} \mathrm{C}$ peak appeared after approximately 2 minutes (Fig. 3), which corresponds to the migration of NPs $\left({ }^{56} \mathrm{Fe}\right)$, represents the response of polymyxin B when interacting with these NPs. This observation shows the unique role of element specific ICP-MS detection, allowing for the detailed study of polymyxin B interactions with NPs under physiological conditions. On the other hand, the "carbon" content corresponding to the injected amount of $\mathrm{Fe}_{2} \mathrm{O}_{3} @ \mathrm{SiO}_{2} \mathrm{COOH}$ 
NPs was too low to be distinguished from the background signal of the running buffer with increasing concentrations of polymyxin B. Furthermore, no ${ }^{12} \mathrm{C}$ peak of NPs was detected for 0 mol.L $\mathrm{L}^{-1}$ of polymyxin $\mathrm{B}$.

Finally, the dependencies of NP mobilities on polymyxin B concentration were linearized according to the Scatchard equation (see the experimental section and Fig. 2B). Again, the two interaction regions for low and high polymyxin B concentrations were observed (Tab. 1). The first region (low polymyxin B concentrations) is represented with quite high interaction constant and with the stoichiometry (0.7) where a less number of polymyxin B molecules interact with one nanoparticle. The second region (high polymyxin B concentrations), on the other hand, acts with quite low interaction constant but with the stoichiometry (3.5) where more polymyxin B molecules interact with the nanoparticle. In this second region, the significant decrease of surface charge of $\mathrm{Fe}_{2} \mathrm{O}_{3} @ \mathrm{SiO}_{2} \mathrm{COOH}$ NPs can be also supposed due to their interaction with more molecules of positively charged polymyxin B (pK values are higher than nine [54]). This is also experimentally proved by the decrease of NPs' mobility (Fig. 2A) and increase of NPs' peak width (modification of NPs leads to the increase of peak width [55]). Interestingly, the effect of polymyxin $\mathrm{B}$ concentration on $\mathrm{Fe}_{2} \mathrm{O}_{3} @ \mathrm{SiO}_{2} \mathrm{COOH}$ NPs is not gradual but it has a drop forming the two interacting regions but this seems to be quite common with NPs [56, 57].

\section{Conclusions}

In this work, interactions between $\mathrm{Fe}_{2} \mathrm{O}_{3} @ \mathrm{SiO}_{2} \mathrm{COOH}$ NPs and polymyxin B sulfate were studied using CE-ICP-MS to prove that these NPs can be used for capturing polymyxin B in a microdevice to test bacterial resistance. The precise analysis of the interactions was possible due to the analysis of different isotopes using ICP-MS. ${ }^{54} \mathrm{Fe},{ }^{56} \mathrm{Fe},{ }^{57} \mathrm{Fe}$ isotopes were used for detection of NPs, ${ }^{34} \mathrm{~S}$ isotope for the electroosmosis, and ${ }^{12} \mathrm{C}$ isotope reflected the interaction of polymyxin B with the NPs. The analysis of the interaction plot showed two interaction regions with a stoichiometry of 0.7 and 3.5. This can be explained by the drop decrease of electrostatic repulsion between NPs and polymyxin B with increasing polymyxin B concentration. Moreover, in the view of the microdevice for testing the bacterial resistance, the optimization of polymyxin B concentration is necessary. The successful capture of polymyxin B will only happen with low polymyxin B concentrations, where the higher interaction constant was found. Here, the NPs forms also quite sharp CE zone representing their stable dispersion. This is contrary to the fact that the "non-stable" dispersion of NPs 
1 (larger and "hairy" peaks) would probably be easily stacked in the channel with the

2 application of a magnetic field. However, the power of the interactions in this second region

3 of polymyxin B concentrations is not high enough to successfully capture polymyxin B.

4

\section{Acknowledgements}

6 The financial support of the research by the Ministry of Education, Youth and Sports of the

7 Czech Republic (projects NPU LO 1305 and Nano4Future

8 CZ.02.1.01/0.0/0.0/16_19/0000754) and the Czech Science Foundation (project 16-23938Y)

9 is gratefully acknowledged. The authors acknowledge financial support from the

10 European commission for the postdoctoral funding of Dr. Emilie Secret on the European

11 Union Horizon 2020 Research and Innovation Program under the project MAGNEURON (grant agreement no. 686841). 


\section{References}

[1] H. Qu, S.W. Linder, T.K. Mudalige, Surface coating and matrix effect on the electrophoretic mobility of gold nanoparticles: a capillary electrophoresis-inductively coupled plasma mass spectrometry study. Anal. Bioanal. Chem. 409 (2017) 979-988.

[2] S. Deguchi, T. Yamazaki, S. Mukai, R. Usami, K. Horikoshi, Stabilization of C-60 nanoparticles by protein adsorption and its implications for toxicity studies. Chem. Res. Toxicol. 20 (2007) 854-858.

[3] B. Samanta, H. Yan, N.O. Fischer, J. Shi, D.J. Jerry, V.M. Rotello, Protein-passivated Fe3O4 nanoparticles: low toxicity and rapid heating for thermal therapy. J. Mater. Chem. 18 (2008) 1204-1208.

[4] I. Lynch, T. Cedervall, M. Lundqvist, C. Cabaleiro-Lago, S. Linse, K.A. Dawson, The nanoparticle - protein complex as a biological entity; a complex fluids and surface science challenge for the 21st century. Adv. Colloid. Interfac. 134-135 (2007) 167-174.

[5] P. Aggarwal, J.B. Hall, C.B. McLeland, M.A. Dobrovolskaia, S.E. McNeil, Nanoparticle interaction with plasma proteins as it relates to particle biodistribution, biocompatibility and therapeutic efficacy. Adv. Drug Deliver. Rev. 61 (2009) 428-437.

[6] D.M. Zhang, O. Neumann, H. Wang, V.M. Yuwono, A. Barhoumi, M. Perham, J.D. Hartgerink, P. Wittung-Stafshede, N.J. Halas, Gold nanoparticles can induce the formation of protein-based aggregates at physiological pH. Nano Lett. 9 (2009) 666671.

[7] C.C. You, M. De, G. Han, V.M. Rotello, Tunable inhibition and denaturation of alphachymotrypsin with amino acid-functionalized gold nanoparticles. J. Am. Chem. Soc. 127 (2005) 12873-12881.

[8] H. Bayraktar, P.S. Ghosh, V.M. Rotello, M.J. Knapp, Disruption of protein-protein interactions using nanoparticles: inhibition of cytochrome c peroxidase. Chem. Commun. (2006) 1390-1392.

[9] N. Li, S. Zeng, L. He, W.W. Zhong, Probing nanoparticle-protein interaction by capillary electrophoresis. Anal. Chem. 82(17) (2010) 7460-7466.

[10] M. Ruzicka, D. Koval, J. Vavra, P.E. Reyes-Gutierrez, F. Teply, V. Kasicka, Interactions of of helquats with chiral acidic aromatic analytes investigated by partialfilling affinity capillary electrophoresis. J. Chromatogr. A 1467 (2016) 417-426.

[11] S.H.D. Lacerda, J.J. Park, C. Meuse, D. Pristinski, M.L. Becker, A. Karim, J.F. Douglas, Interaction of gold nanoparticles with common human blood proteins. ACS Nano 4 (2010) 365-379. 
[12] Z. Chen, S.G. Weber, Determination of binding constants by affinity capillary electrophoresis, electrospray ionization mass spectrometry and phase-distribution methods. Trend. Anal. Chem. 27 (2008) 738-748.

[13] M.P. Williamson, Using chemical shift perturbation to characterise ligand binding. Prog. Nucl. Mag. Res. Sp. 73 (2013) 1-16.

[14] T. Cedervall, I. Lynch, S. Lindman, T. Berggard, E. Thulin, H. Nilsson, K.A. Dawson, S. Linse, Understanding the nanoparticle-protein corona using methods to quantify exchange rates and affinities of proteins for nanoparticles. Proc. Natl. Acad. Sci. USA 104 (2007) 2050-2055.

[15] P. Mura, Analytical techniques for characterization of cyclodextrin complexes in aqueous solution: A review. J. Pharm. Biomed. Anal. 101 (2014) 238-250.

[16] M. Matczuk, J. Legat, S.N. Shtykov, M. Jarosz, A.R. Timerbaev, Characterization of the protein corona of gold nanoparticles by an advanced treatment of CE-ICP-MS data. Electrophoresis 37 (2016) 2257-2259.

[17] M. Růžička, M. Jirásek, F. Teplý, D. Koval, V. Kašička, Study of deoxyribonucleic acid-ligand interactions by partial filling affinity capillary electrophoresis. J. Chromatogr. A 1349 (2014) 116-121.

[18] A. Pallotta, A. Boudier, P. Leroy, I. Clarot, Characterization and stability of gold nanoparticles depending on their surface chemistry: Contribution of capillary zone electrophoresis to a quality control. J. Chromatogr. A 1461 (2016) 179-184.

[19] F.F. Liu, J.H. Wang, L. Yang, L. Liu, S.M. Ding, M.L. Fu, L.H. Deng, L.Q. Gao, Developing a fluorescence-coupled capillary electrophoresis based method to probe interactions between QDs and colorectal cancer targeting peptides. Electrophoresis 37 (2016) 2170-2174.

[20] D.A. Grela, V. Zannoni, N.M. Vizioli, Studying the interaction between peptides and polymeric nanoparticles used as pseudostationary phase in capillary electrochromatography. Microchem. J. 130 (2017) 153-156.

[21] M. Matczuk, J. Legat, A.R. Timerbaev, M. Jarosz, A sensitive and versatile method for characterization of protein-mediated transformations of quantum dots. Analyst 141 (2016) 2574-2580.

[22] J.H. Wang, C.C. Zhang, L. Liu, K.A. Kalesh, L. Qiu, S.M. Ding, M.L. Fu, L.Q. Gao, P.J. Jiang, A capillary electrophoresis method to explore the self-assembly of a novel polypeptide ligand with quantum dots. Electrophoresis 37 (2016) 2156-2162. 
[23] J. Legat, M. Matczuk, A. Timerbaev, M. Jarosz, CE Separation and ICP-MS Detection of Gold Nanoparticles and Their Protein Conjugates. Chromatographia 80 (2017) 16951700.

[24] G. Ramirez-Garcia, F. d'Orlye, S. Gutierrez-Granados, M. Martinez-Alfaro, N. Mignet, C. Richard, A. Varenne, Electrokinetic Hummel-Dreyer characterization of nanoparticle-plasma protein corona: The non-specific interactions between PEGmodified persistent luminescence nanoparticles and albumin. Colloid. Surf. B 159 (2017) 437-444.

[25] M. Matczuk, J. Legat, F. Scaletti, L. Messori, A.R. Timerbaev, M. Jarosz, The fate of differently functionalized gold nanorods in human serum: A response from capillary electrophoresis-inductively coupled plasma mass spectrometry. J. Chromatogr A 1499 (2017) 222-225.

[26] A.L. Marie, N.T. Tran, E.P. Bianchini, F. Sailer, S. Pautus, T. Abache, J.L. Plantier, R. Urbain, D. Borgel, M. Taverna, A fast capillary electrophoresis method to assess the binding affinity of recombinant antithrombin toward heparin directly from cell culture supernatants. J. Pharm. Biomed. Anal. 111 (2015) 64-70.

[27] S. Ehala, E. Marklik, P. Toman, V. Kasicka, ACE applied to the quantitative characterization of benzo-18-crown-6-ether binding with alkali metal ions in a methanol-water solvent system. Electrophoresis 31 (2010) 702-708.

[28] F. Varenne, M. Bourdillon, M. Meyer, Y. Lin, M. Brellier, R. Baati, L.J. Charbonniere, A. Wagner, E. Doris, F. Taran, A. Hagege, Capillary electrophoresis-inductively coupled plasma-mass spectrometry hyphenation for the determination at the nanogram scale of metal affinities and binding constants of phosphorylated ligands. J. Chromatogr. A 1229 (2012) 280-287.

[29] L.H. Liu, B. He, Q. Liu, Z.J. Yun, X.T. Yan, Y.M. Long, G.B. Jiang, Identification and accurate size characterization of nanoparticles in complex media. Angew. Chem. Int. Ed. 53 (2014) 14476-14479.

[30] H.P. Jen, Y.C. Tsai, H.L. Su, Y.Z. Hsieh, On-line preconcentration and determination of ketamine and norketamine by micellar electrokinetic chromatography - Complementary method to gas chromatography/mass spectrometry. J. Chromatogr. A 1111 (2006) 159165.

[31] C. Simo, V. Garcia-Canas, A. Cifuentes, Chiral CE-MS. Electrophoresis 31 (2010) 1442-1456. 
[32] B. Meermann, V. Nischwitz, ICP-MS for the analysis at the nanoscale - a tutorial review. J. Anal. At. Spectrom. 33 (2018) 1432-1468.

[33] S. Carter, R. Clough, A. Fisher, B. Gibson, B. Russell, J. Waack, Atomic spectrometry update: review of advances in the analysis of metals, chemicals and materials. J. Anal. At. Spectrom. 33 (2018) 1802-1848.

[34] K. Polec-Pawlak, J.K. Abramski, O. Semenova, C.G. Hartinger, A.R. Timerbaev, B.K. Keppler, M. Jarosz, Platinum group metallodrug-protein binding studies by capillary electrophoresis - inductively coupled plasma-mass spectrometry: A further insight into the reactivity of a novel antitumor ruthenium(III) complex toward human serum proteins. Electrophoresis 27 (2006) 1128-1135.

[35] C.G. Hartinger, A.R. Timerbaev, B.K. Keppler, Capillary electrophoresis in anti-cancer metallodrug research: Advances and future challenges. Electrophoresis 24 (2003) 20232037.

[36] A.L. Rosen, G.M. Hieftje, Inductively coupled plasma mass spectrometry and electrospray mass spectrometry for speciation analysis: applications and instrumentation. Spectrochim. Acta B 59 (2004) 135-146.

[37] A. Prange, D. Profrock, Application of CE-ICP-MS and CE-ESI-MS in metalloproteomics: challenges, developments, and limitations. Anal. Bioanal. Chem. 383 (2005) 372-389.

[38] J.E. Sonke, V.J.M. Salters, Capillary electrophoresis-high resolution sector field inductively coupled plasma mass spectrometry. J. Chromatogr. A 1159 (2007) 63-74.

[39] H.O. Qu, T.K. Mudalige, S.W. Linder, Capillary electrophoresis coupled with inductively coupled mass spectrometry as an alternative to cloud point extraction based methods for rapid quantification of silver ions and surface coated silver nanoparticles. J. Chromatogr. A 1429 (2016) 348-353.

[40] H. Li, S. van den Driesche, F. Bunge, B. Yang, M. J. Vellekoop, Optimization of onchip bacterial culture conditions using the Box-Behnken design response surface methodology for faster drug susceptibility screening. Talanta 194 (2019) 627-633.

[41] L.L. Wang, C. Hu, L.Q. Shao, The antimicrobial activity of nanoparticles: present situation and prospects for the future. Int. J. Nanomed. 12 (2017) 1227-1249.

[42] A. Panáček, L. Kvítek, M. Smékalová, R. Večeřová, M. Kolář, M. Roderová, F. Dyčka, M. Šebela, R. Prucek, O. Tomanec, R. Zbořil, Bacterial resistance to silver nanoparticles and how to overcome it. Nature Nanotechnol. 13 (2018) 65-71. 
[43] A. Šustková, E. Drastíková, K. Konderlová, S. Suetzl, L. Hárendarčíková, J. Petr, Rapid production of PDMS microdevices for microfluidics and separations by 3D printed scaffolds removal, in preparation.

[44] I. Ihara, K. Toyoda, N. Beneragama, K. Umetsu, Magnetic separation of antibiotics by electrochemical magnetic seeding. J. Phys. 156 (2009) 012034.

[45] T. Wang, S. Ai, Y. Zhou, Z. Luo, C. Dai, Y. Yang, J. Zhang, H. Huang, S. Luo, L. Luo, Adsorption of agricultural wastewater contaminated with antibiotics, pesticides and toxic metals by functionalized magnetic nanoparticles. J. Environ. Chem. Enginner. 6 (2018) 6468-6478.

[46] A M. Laurencin, T. Georgelin, B. Malezieux, J.-M. Siaugue, C. Menager, Interactions between giant unilamellar vesicles and charged core-shell magnetic nanoparticles. Langmuir 26 (2010) 16025-16030.

[47] O. Makrygenni, E. Secret, A. Michel, D. Brouri, V. Dupuis, A. Proust, J.-M. Siaugue, R. Villanneau, Heteropolytungstate-decorated core-shell magnetic nanoparticles: A covalent strategy for polyoxometalate-based hybrid nanomaterials. J. Colloid Interfac. Sci. 514 (2018) 49-58.

[48] R. Massart, Preparation of aqueous magnetic liquids in alkaline and acidic media. IEEE Trans. Magn. 17 (1981) 1247-1248.

[49] N. Fauconnier, A. Bee, J. Roger, J.N. Pons, Adsorption of gluconic and citric acids on maghemite particles in aqueous medium. Prog. Colloid. Polym. Sci. 100 (1996) 212216.

[50] T. Le Saux, A. Varenne, F. Perreau, T. Siret, S. Duteil, L. Duhau, P. Gareil, Determination of the binding parameters for antithrombin-heparin fragment systems by affinity and frontal analysis continuous capillary electrophoresis. J. Chromatogr. A 1132 (2006) 289-296.

[51] C.X. Jiang, D.W. Armstrong, Use of CE for the determination of binding constants. Electrophoresis 31 (2010) 17-27.

[52] T. Le Saux, H. Hisamoto, S. Terabe, Measurement of monomolecular binding constants of neutral phenols into the beta-cyclodextrin by continuous frontal analysis in capillary and microchip electrophoresis via a competitive assay. J. Chromatogr. A 1104 (2006) 352-358.

[53] K.L. Rundlett, D.W. Armstrong, Methods for the estimation of binding constants by capillary electrophoresis. Electrophoresis 18 (1997) 2194-2202. 
[54] D. Petsch, T.C. Beeskow, F.B. Anspach, W.D. Deckwer, Membrane adsorbers for selective removal of bacterial endotoxin. J. Chromatogr. B 693 (1997) 79-91.

[55] J. Petr, B. Teste, S. Descroix, J.-M. Siaugue, P. Gareil, A. Varenne, Separation of $\alpha-$ lactalbumin grafted- and non-grafted maghemite core/silica shell nanoparticles by capillary zone electrophoresis. Electrophoresis 31 (2010) 2754-2761.

[56] K. Rezwan, L.P. Meier, M. Rezwan, J. Voros, M. Textor, L.J. Gauckler, Bovine serum albumin adsorption onto colloidal A12O3 particles: A new model based on zeta potential and UV-Vis measurements. Langmuir 20 (2004) 10055-10061.

[57] K. Rezwan, A.R. Studart, J. Voros, L.J. Gauckler, Change of zeta potential of biocompatible colloidal oxide particles upon adsorption of bovine serum albumin and lysozyme. J. Phys. Chem. B 109 (2005) 14469-14474.

5

.

8

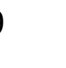

1 


\section{Figure captions}

2

3 Figure 1: An example of the CE-ICP-MS analysis of the $\mathrm{Fe}_{2} \mathrm{O}_{3} @ \mathrm{COOH}$ NPs with different 4 polymyxin $\mathrm{B}$ concentrations

5 BGE: $25 \mathrm{mM}$ phosphate buffer $\mathrm{pH} 7.4$, separation at $25 \mathrm{kV}$

6

7 Figure 2: A, The dependence of NPs effective mobilities on concentration of polymyxin B, 8 B, Scatchard plot

9 BGE: $25 \mathrm{mM}$ phosphate buffer $\mathrm{pH}$ 7.4; $\mathrm{SD}$ values are given in parenthesis $(\mathrm{n}=5)$; for the explanation, see the theory, part 2.4

Figure 3: Pressure-assisted ACE-ICP-MS for confirmation of interaction of NPs with 13 polymyxin $\mathrm{B}$

14 BGE: $25 \mathrm{mM}$ phosphate buffer $\mathrm{pH} 7.4$, separation at $25 \mathrm{kV}$, pressure of 50 mbar, polymyxin B concentration: $300 \times 10^{-7}$ mol. $\mathrm{L}^{-1}$ 


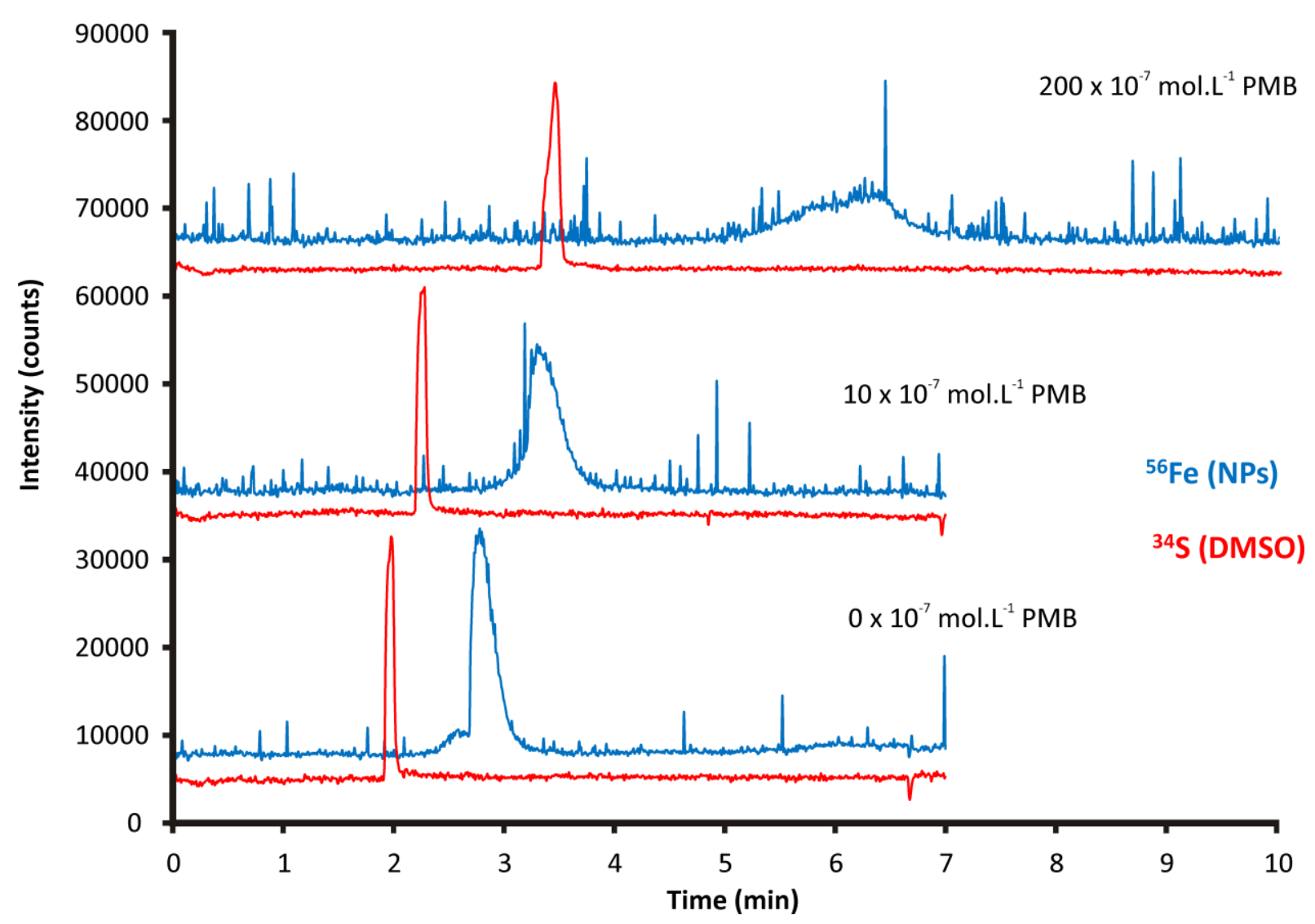

2 Figure 1: An example of the CE-ICP-MS analysis of the $\mathrm{Fe}_{2} \mathrm{O}_{3} @ \mathrm{COOH}$ NPs with different 3 polymyxin $\mathrm{B}$ concentrations

4 BGE: $25 \mathrm{mM}$ phosphate buffer $\mathrm{pH} 7.4$, separation at $25 \mathrm{kV}$ 


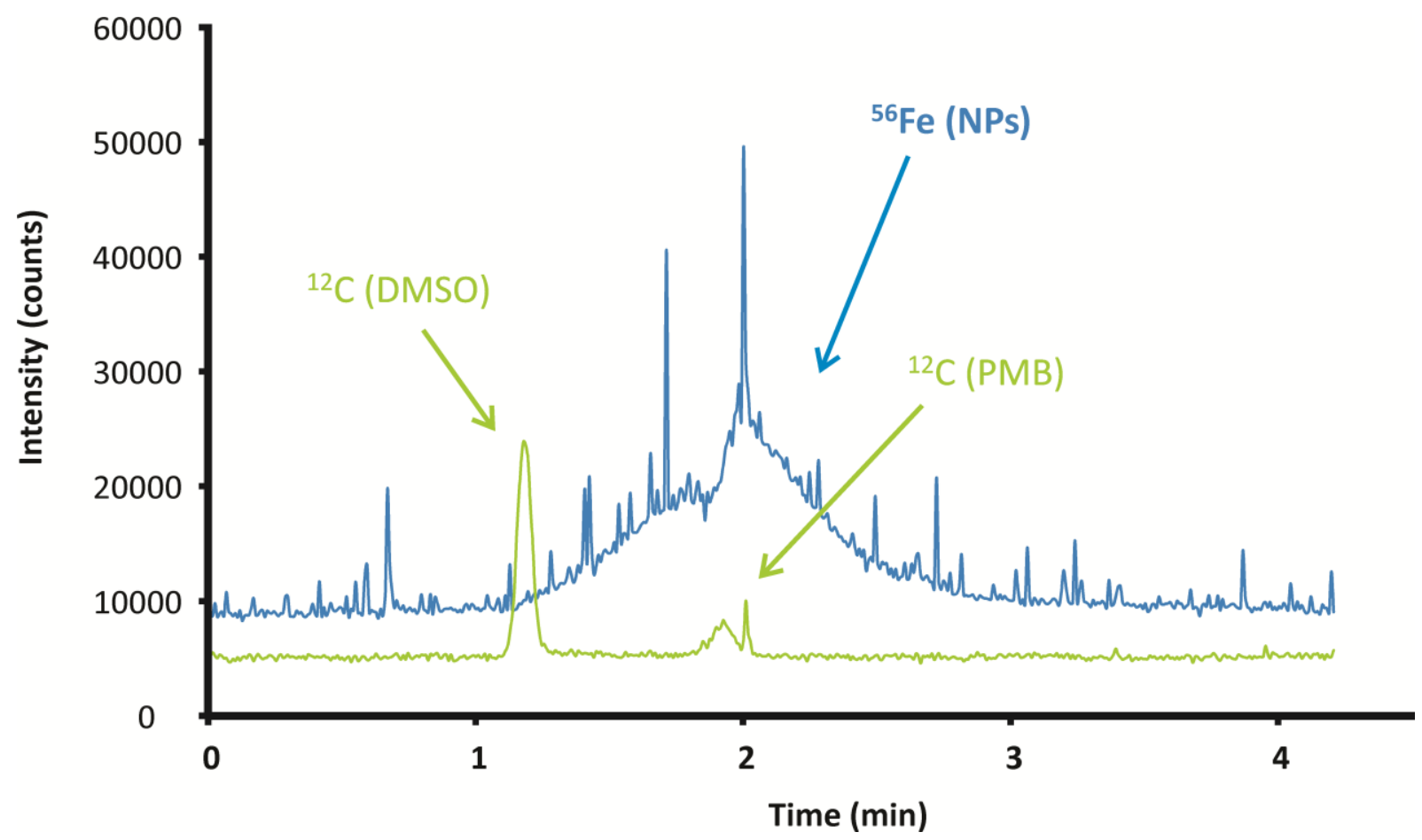

2 Figure 2: A, The dependence of NPs effective mobilities on concentration of polymyxin B,

3 B, Scatchard plot

4 BGE: $25 \mathrm{mM}$ phosphate buffer $\mathrm{pH}$ 7.4; $\mathrm{SD}$ values are given in parenthesis $(\mathrm{n}=5)$; for the

5 explanation, see the theory, part 2.4

6 

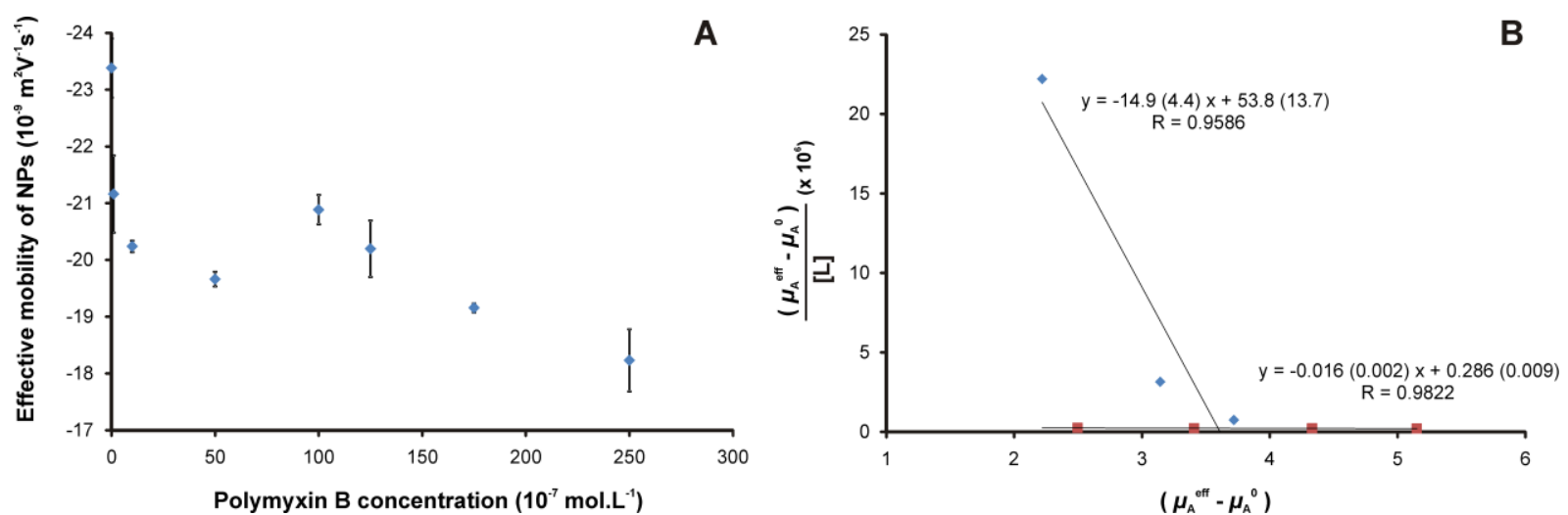

2 Figure 3: Pressure-assisted ACE-ICP-MS for confirmation of interaction of NPs with

3 polymyxin $\mathrm{B}$

4 BGE: $25 \mathrm{mM}$ phosphate buffer $\mathrm{pH} 7.4$, separation at $25 \mathrm{kV}$, pressure of 50 mbar, polymyxin

5 B concentration: $300 \times 10^{-7}$ mol.L $\mathrm{L}^{-1}$

6 
1 Table 1: Interaction and stoichiometry results

2

\begin{tabular}{|l|l|l|}
\hline $\begin{array}{l}\text { Concentration of } \\
\text { polymyxin B }\end{array}$ & $\mathrm{K}_{\mathrm{b}}\left(\mathrm{M}^{-1}\right)^{*}$ & $\mathrm{n}^{*}$ \\
\hline $1-50 \times 10^{-7} \mathrm{~mol} . \mathrm{L}^{-1}$ & $14.9(4.4) \times 10^{6}$ & $0.7(0.3)$ \\
\hline $100-250 \times 10^{-7} \mathrm{~mol} . \mathrm{L}^{-1}$ & $16.0(2.2) \times 10^{3}$ & $3.5(0.5)$ \\
\hline
\end{tabular}

$3 *$ standard deviations are displayed in parenthesis

4

5

6 